Check for updates

Cite this: RSC Adv., 2019, 9, 37608

Received 11th October 2019

Accepted 13th November 2019

DOI: $10.1039 / c 9 r a 08300 f$

rsc.li/rsc-advances

\section{Selective carboxylation versus layer-by-layer unsheathing of multi-walled carbon nanotubes: new insights from the reaction with boiling nitrating mixture $\uparrow$}

\author{
Anna Kolanowska, ${ }^{a}$ Patrycja Wąsik, ${ }^{a}$ Wojciech Zięba, ${ }^{b}{ }^{b}$ Artur Piotr Terzyk ${ }^{b}$ \\ and Stawomir Boncel (iD *a
}

\begin{abstract}
We have studied the oxidation of multi-wall carbon nanotubes (MWCNTs) by boiling them in a nitrating mixture composed of conc. $\mathrm{HNO}_{3} / \mathrm{H}_{2} \mathrm{SO}_{4}(\mathrm{v} / \mathrm{v}=1 / 3)$. By analysis of the morphology and surface physicochemistry of the oxidation products as a function of MWCNT treatment time, we have revealed two interrelated phenomena. Firstly, the most outer walls were becoming more functionalized with carboxylic groups to the point of quasi-saturation where, secondly, oxidized MWCNTs could be desheathed uncovering the yet non-functionalized wall. These phenomena were manifested by the periodic-like nature of functionalization and de-functionalization. In the products of MWCNT oxidation the number of graphitized MWCNT walls was determined by HR-TEM while quantification of oxygen functionalities was performed via Boehm titration. The above techniques coupled with the analysis of zeta potential and Raman spectroscopy allowed us to propose a pseudo- $1^{\text {st }}$ order kinetic model for MWCNT oxidation translatable to other $\mathrm{sp}^{2}-\mathrm{C}$ allotropes. The findings mean that prolonged oxidation does not necessarily yield nanotubes of higher levels of functionalization. The final outcome is of great relevance in all fields of MWCNT applications from medicine to sensors to nanomaterials engineering.
\end{abstract}

\section{Introduction}

Controllable surface functionalization of carbon nanotubes $(\mathrm{CNTs})^{1}$ remains an unceasing challenge for chemists. Particularly, control over the kinetics and the selectivity of introducing oxygen functional groups onto CNTs is of high importance. ${ }^{2}$ The significance derives from the fact that numerous applications, from biomedicine (drug/gene delivery, cell scaffolds) to electrical engineering to sensors, require CNTs of precise stoichiometry, tunable hydrophilization and biocompatibility. ${ }^{3}$ Nearly three decades of research has shown that oxidation of CNTs is the most commonly reported method to overcome the problems related to their poor dispersibility, limited solvent/matrix compatibility and purity. ${ }^{4,5}$ Oxidation, apart from functionalization in the general sense, could also lead to significant changes in the CNT morphology such as thinning, cutting or unzipping (to graphenoid products). ${ }^{6,7}$ It is therefore crucial to understand the process of CNT oxidation as it could yield

${ }^{a}$ Department of Organic Chemistry, Bioorganic Chemistry and Biotechnology, Silesian University of Technology, Krzywoustego 4, 44-100 Gliwice, Poland. E-mail: slawomir. boncel@polsl.pl

${ }^{b}$ Faculty of Chemistry, Physicochemistry of Carbon Materials Research Group, Nicolaus Copernicus University in Toruń, Gagarin Street 7, 87-100 Toruń, Poland

$\dagger$ Electronic supplementary information (ESI) available. See DOI: 10.1039/c9ra08300f control over this process, typically considered as a 'black-box' in terms of the complex molecular mechanisms. ${ }^{\mathbf{2}}$

By now, there have been several trials addressing the controllable oxidation of CNTs in the liquid phase. Datsyuk et al. ${ }^{9}$ studied the effect of oxidation of multi-wall CNTs (MWCNTs) (synthesised by c-CVD, purity $80 \%$, outer diameter $d=10-20 \mathrm{~nm}$, length $l=0.7 \mu \mathrm{m}$ ) via acidic (nitric acid and a mixture of sulfuric acid/hydrogen peroxide) and basic (ammonium hydroxide, hydrogen peroxide) agents. After oxidation [reflux, $48 \mathrm{~h}$ for conc. $\mathrm{HNO}_{3}$, room temperature; $5 \mathrm{~h}$ for $\mathrm{H}_{2} \mathrm{SO}_{4} /$ conc. $\mathrm{H}_{2} \mathrm{O}_{2}$ ('piranha') and $80{ }^{\circ} \mathrm{C}, 5 \mathrm{~h}$ for the mixture of $\mathrm{NH}_{3(\mathrm{aq})}$ and $\mathrm{H}_{2} \mathrm{O}_{2}$, concentration of carboxylic groups increased from 1.0 (MWCNTs purified with conc. $\left.\mathrm{HCl}_{\mathrm{aq}}\right)$ to $1.6\left(\mathrm{NH}_{3(\mathrm{aq})}, \mathrm{H}_{2} \mathrm{O}_{2}\right), 2.0\left(\mathrm{H}_{2} \mathrm{SO}_{4} / \mathrm{H}_{2} \mathrm{O}_{2}\right)$ and $3.7 \mathrm{mmol} \mathrm{g}^{-1}\left(\mathrm{HNO}_{3}\right)$. Moreover, oxidation under acidic conditions produced shortened and more defective CNTs, while under basic conditions oxidation removed the residues of amorphous carbon and metal oxides leaving the nanotubes intact. Goh et al. ${ }^{\mathbf{1 0}}$ have studied the effect of oxidation time on dispersibility of MWCNTs (prepared by c-CVD) in solvents (water, $n$-hexane and ethanol). MWCNTs were oxidized using a mixture of $\mathrm{H}_{2} \mathrm{SO}_{4}$ and $\mathrm{HNO}_{3}(1: 4 ; \mathrm{v} / \mathrm{v})$ in reflux for 2,4 and $6 \mathrm{~h}$. The concentration of $\mathrm{COOH}$ groups changed from $0.8 \mathrm{mmol} \mathrm{g}^{-1}$ (pristine) to $1.75(2 \mathrm{~h})$, $2.00(4 \mathrm{~h})$ and $2.50 \mathrm{mmol} \mathrm{g}^{-1}(6 \mathrm{~h})$. Oxidized MWCNTs (OMWCNTs) formed stable dispersions in ethanol and water while they were indispersible in $n$-hexane confirming polar 
character of O-MWCNTs and build-up of 3D network of hydrogen bonding. Rosca et al. ${ }^{11}$ have monitored the weight of nanotube substrates and products as well as dispersibility of O-MWCNTs after oxidation using nitric acid. MWCNTs $(d=20-40 \mathrm{~nm}, l=$ 5-20 $\mu \mathrm{m})$ were refluxed in $\mathrm{HNO}_{3}(60 \%)$ from 1-48 $\mathrm{h}$. The enhanced dispersibility was obtained for the samples treated for 24-48 h while $60-90 \%$ of the initial MWCNTs were lost. Additionally, oxidation caused problems with isolation of small diameter MWCNTs (degradation after 24 h oxidation); MWCNTs were also cut (short CNTs were visible at SEM images) and revealed a better alignment after drying in comparison with the pristine MWCNTs. Furthermore, Canete-Rosales et al. ${ }^{\mathbf{1 2}}$ studied the effect of chemical oxidation on two types of MWCNTs: short ( $d=15-45 \mathrm{~nm}, l=1-5 \mu \mathrm{m})$ and long $(d=15-45 \mathrm{~nm}, l=5-20 \mu \mathrm{m})$ ones. The samples were heated in a mixture of conc. $\mathrm{H}_{2} \mathrm{SO}_{4}{ }^{-}$ : $\mathrm{HNO}_{3}(3: 1 ; \mathrm{v} / \mathrm{v})$ for 3 and $6 \mathrm{~h}$ or in $\mathrm{HNO}_{3}$ for $6 \mathrm{~h}$. The concentration of $\mathrm{COOH}$ groups was higher for longer MWCNTs: $1.83 \mathrm{wt} \%$ ( $3 \mathrm{~h}$ nitrating mixture), $2.39 \mathrm{wt} \%$ ( $6 \mathrm{~h}$ nitrating mixture) and 3.38 wt $\%$ ( $6 \mathrm{~h}$ nitric acid). Furthermore, oxidation using $\mathrm{HNO}_{3}$ led to higher amounts of quinone, lactone and anhydride groups whereas nitrating mixture introduced mainly carboxylic groups. Importantly, the oxidation could be applied for the production of graphene nanoribbons..$^{13,14}$ Dimiev et al., while revisiting the mechanism of MWCNT unzipping, have studied the effect of KMnO4 : MWCNTs $(d=40-80 \mathrm{~nm}, l=4-12 \mu \mathrm{m})$ ratio and oxidation time on the structure and composition of the graphene nanoribbon products. The unzipping process involved consecutive intercalation (nanotube swelling), oxidation and exfoliation steps. Intercalation and unzipping occurred in the $\mathrm{KMnO}_{4} / \mathrm{H}_{2} \mathrm{SO}_{4}$ solution, while the full oxidation and exfoliation in water. For the complete MWCNT unzipping, a 0.12 wt. equiv. of $\mathrm{KMnO}_{4}$ was required. Controlling of $\mathrm{KMnO}_{4}:$ MWCNT ratio and the oxidation duration led to the products with a clearly defined number of layers and the oxidation degrees. Kinetics of MWCNT oxidation was also studied in the gas phase (using air and oxygen) ${ }^{15-18}$ but the MWCNT substrate scope was ambiguous and the elaborated models were not transposed to the atomic scales.

Here, we present the new findings on the oxidation of welldefined MWCNTs under harsh conditions in the liquid phase. We demonstrate that the oxidation duration allows controlling a degree of selective carboxylation (functionalization with carboxylic groups), in the background of hydroxylation. At the same time, quenching the reaction mixture at the required step of the MWCNT layer-by-layer unsheathing would allow to control the MWCNT diameter. We therefore clearly show that the progressive layer-by-layer combustion (hence decarboxylation) and selective oxidation are interrelated processes. Importantly, the behaviour of the reactants is presented for the first time within the short time intervals. This disclosure constitutes an important development in the field of CNT functionalization also because numerous previous outcomes from the oxidation studies were performed at one-hour intervals as the shortest periods and in the absence of analysis of morphological MWCNT changes upon the oxidation. We eventually deliver a model of MWCNT oxidation under above harsh conditions showing consequences for the application site of MWCNTs.

\section{Experimental}

\section{Materials}

Commercially available MWCNTs NC7000 ${ }^{\mathrm{TM}}(d=9.6 \mathrm{~nm}, l=$ $1.5 \mu \mathrm{m}, 90 \%$ purity) were purchased from Nanocyl, Belgium. Nitric acid (65\%, pure p.a.), sulfuric acid (98\%, pure p.a.), sodium hydroxide (pure p.a.), sodium carbonate (pure p.a.), sodium bicarbonate (pure p.a.) and hydrochloric acid (35-38\%, pure p.a.) were purchased from Chempur, Poland.

\section{Kinetic studies of MWCNT oxidation toward oxidized MWCNTs (O-MWCNTs)}

MWCNTs $(2.000 \mathrm{~g})$ were mixed with a solution of conc. $\mathrm{HNO}_{3}$ : $\mathrm{H}_{2} \mathrm{SO}_{4}(1: 3 ; \mathrm{v} / \mathrm{v})(52 \mathrm{~mL})$. The reaction mixture was refluxed using the identical heating power supplied by the heating mantle for the periods from 5 to $90 \mathrm{~min}$, and to the time of full gasification of MWCNTs (leaving $\mathrm{Al}_{2} \mathrm{O}_{3}$ as the residue). After cooling down at room temperature ( $15 \mathrm{~min})$, the mixture was quenched by pouring onto distilled water (2 L). O-MWCNTs were filtered off under diminished pressure using a PTFE filter (Merck Millipore; pore size $0.2 \mu \mathrm{m}$ ) and rinsed with distilled water until $\mathrm{pH}$ 7. O-MWCNTs were dried at $85^{\circ} \mathrm{C}$ to the constant weight, that is at least for $12 \mathrm{~h}$.

\section{Characterization}

High-resolution transmission electron microscopy (HR-TEM), thermogravimetry (TGA), Boehm titration and zeta potential measurements were used to characterize the changes in the morphology and surface physicochemistry of MWCNTs and OMWCNTs. HR-TEM images were taken using a transmission electron microscope F20X-TWIN (FEI-Tecnai) operated at 200 $\mathrm{kV}$. One drop of sample dispersion in ethanol (96\%, p.a.) was placed on a copper grid coated with an ultrathin amorphous carbon film, and then dried under ambient conditions. TGA curves were recorded using a LINSEIS STA PT1600 in a heating rate of $10^{\circ} \mathrm{C} \mathrm{min}^{-1}$ under the argon atmosphere. The content of surface oxygen groups in MWCNTs was determined by Boehm titration ${ }^{19}$ and the procedure was as follows: functionalized (and pristine, i.e. blank sample) MWCNTs (60 mg) were dispersed for $48 \mathrm{~h}$ under continuous magnetic stirring in the specified aqueous reaction base solutions: (1) $0.01 \mathrm{M} \mathrm{NaOH}, 60 \mathrm{~mL}$; (2) $0.01 \mathrm{M} \mathrm{Na}_{2} \mathrm{CO}_{3}, 30 \mathrm{~mL}$; (3) $0.01 \mathrm{M} \mathrm{NaHCO}_{3}, 60 \mathrm{~mL}$. The mixture was filtrated using a $0.2 \mu \mathrm{m}$-PTFE filter and then $10 \mathrm{~mL}$ (or $5 \mathrm{~mL}$ in the case of $\mathrm{Na}_{2} \mathrm{CO}_{3}$ ) of the appropriate filtrates was titrated with $0.01 \mathrm{M} \mathrm{HCl}_{\mathrm{aq}}(20 \mathrm{~mL})$. $\mathrm{pH}$ of the final solutions was measured using a pH-meter (EcoTestr 2). Each titration was performed in triplicate. As blank samples $10 \mathrm{~mL}$ of each reaction base $\left(5 \mathrm{~mL}\right.$ in the case of $\left.\mathrm{Na}_{2} \mathrm{CO}_{3}\right)$ were used. Zeta potential (at $25{ }^{\circ} \mathrm{C}$ ) was measured using Nano Plus HD (Micromeritics, USA) for $\mathrm{pH}=7.0 .5 \mathrm{mg}$ of CNTs was dispersed in $30 \mathrm{~mL}$ of $0.1 \mathrm{mM} \mathrm{KCl}$ ( $\mathrm{pH}$ of the suspension was adjusted using standard solutions of $\mathrm{HCl}_{\mathrm{aq}}$ or $\mathrm{NaOH}_{\mathrm{aq}}$ ).

\section{Results and discussion}

As the MWCNT oxidizing agent a standard nitrating mixture was used. It was composed from a mixture of concentrated 
nitric(v) (65 wt\%) and sulphuric(vi) (98 wt\%) acids in a volumetric ratio $v / v=1 / 3$. This oxidizing system was frequently applied in the laboratory practice for pre-functionalization of CNTs with carboxylic and/or hydroxyl groups. On the other hand, it has not been systematically studied in terms of the post-treatment nanotube morphology. In order to carefully and systematically track the kinetics of MWCNT oxidation, we have performed the reactions in different periods of time but otherwise identical conditions, i.e. under reflux in the mixture of the above acids (Fig. 1). To comprehensively analyse the products of MWCNT oxidation, a set of various, complementary analytical techniques was used. And so, (a) HR-TEM allowed to reveal a number of well-graphitized CNT walls, (b) pyrolytic TGA was applied to quantify functionalization degrees, (c) Raman spectroscopy was used to identify $\mathrm{sp}^{3}$-type lattice/wall disorders in the background of aromatic $\mathrm{sp}^{2}$-carbon atoms, (d) Boehm titration allowed to selectively quantify carboxylic and hydroxyl groups, and (e) zeta potential measurements cross-verified TGA and titration results (Fig. 1, techniques).

As the reference MWCNT material, we have selected commercially available nanotubes MWCNTs of well-defined morphology, i.e. Nanocyl $\mathrm{NC}^{2} 000^{\mathrm{TM}}$ produced in an industrial scale in a c-CVD fluidized bed reactor $(90 \mathrm{wt} \%$ nanotube product, $\sim 9 \mathrm{wt} \% \mathrm{Al}_{2} \mathrm{O}_{3}$ and $\sim 1 \mathrm{wt} \%$ of total $\left.\mathrm{Fe}\right) .{ }^{20}$ MWCNTs were refluxed in the nitrating mixture from 5 to 90 min time intervals. Each heating time up to the boiling point (bp) of the reaction mixture was identical (7 min) while the start-point of the releasing brown fumes of nitrogen oxide $\left(\mathrm{NO}_{2}\right)$ could be plainly noticed, after 3 min of heating, identifying progress of the oxidation. The end of $\mathrm{NO}_{2}$ release, observed as the clear cut-off, could be determined at $\sim 30 \mathrm{~min}$. Afterwards, all of the post-reaction mixtures were allowed to cool down under the same conditions. O-MWCNTs as the main reaction products were isolated as black precipitates, washed with water and dried to the constant weight which was nearly equal to the initial weight of MWCNTs (see Table 1). The products after drying were hard and brittle solids due to formation of three-dimensional network of hydrogen bonds containing water. Importantly, as confirmed by UV-Vis and NMR spectroscopy, no polyaromatic hydrocarbons (PAHs), fulvic acids or

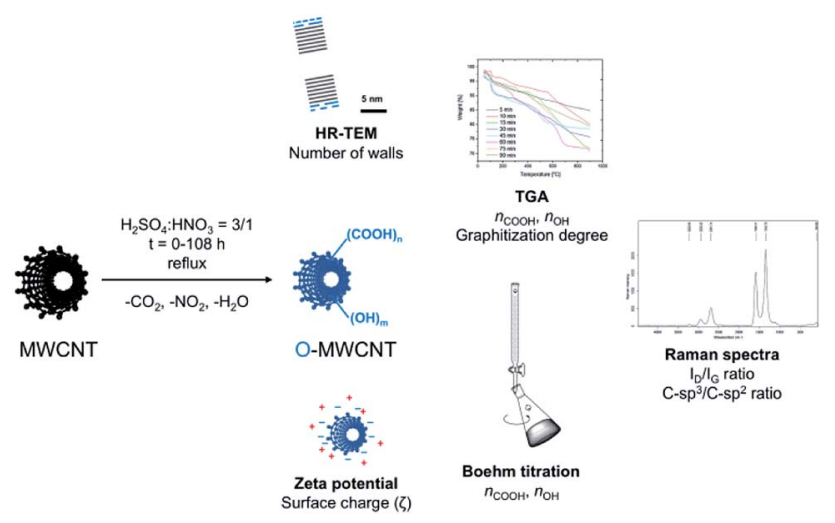

Fig. 1 Treatment of MWCNTs using boiling nitrating mixture toward O-MWCNTs products of various surface functionalization/morphology and the analytical techniques applied thereto.
Table 1 Number of well-graphitized MWCNT walls versus the oxidation time

\begin{tabular}{llll}
\hline Time & No. of walls & No. of walls $(\min : \max )$ & $\begin{array}{l}\text { Weight of isolated } \\
\text { O-MWCNTs, } g\end{array}$ \\
\hline 0 & $15.0 \pm 2.0$ & $(13: 17)$ & 0.000 \\
5 & $14.7 \pm 1.2$ & $(12: 16)$ & 1.020 \\
10 & $12.5 \pm 1.4$ & $(11: 15)$ & 1.024 \\
15 & $12.2 \pm 1.8$ & $(9: 15)$ & 1.041 \\
30 & $11.3 \pm 1.8$ & $(9: 14)$ & 1.014 \\
45 & $9.9 \pm 1.6$ & $(7: 13)$ & 1.010 \\
60 & $9.2 \pm 0.8$ & $(7: 10)$ & 1.019 \\
75 & $8.8 \pm 1.2$ & $(6: 10)$ & 1.022 \\
90 & $8.1 \pm 1.2$ & $(5: 10)$ & 1.008 \\
\hline
\end{tabular}

MWCNT wall-debris, such as fluorescent carbon quantum dots or graphenoids, were identified as side- or by-products neither in the filtrate nor on the O-MWCNT surface. Hence, no risk of the overestimation of functional groups in the solid product occurred.

Initially, morphology of MWCNTs and O-MWCNTs was studied using high resolution transmission electron microscopy (HR-TEM) (Fig. 2). Under analogous magnification one could immediately notice along the nanotube length, apart from wellgraphitized hence countable MWCNT walls, numerous grooves and disordered $\mathrm{sp}^{3}$-carbon layers. A careful look at the purely $\mathrm{sp}^{2}$ developed nanotube walls allowed seeing a clear tendency of the decreasing number of MWCNT walls with time of oxidation. Indeed, the number of MWCNT walls - while starting from pristine to 90 min-treated MWCNTs - decreased(on the average) from 15 to 8 walls, respectively. Table 1 shows a more detailed relationship - expressed by a statistical TEM analysis of 50 individual and distinguishable, i.e. visibly separable one-fromother (measured one-by-one) nanotubes for a given O-MWCNT batch - between the number of MWCNT walls and the period of oxidation.

Clearly, the prolonged oxidation led to a progressive digestion and the eventual gasification of the nanotube walls in a 'layer-by-layer' manner leading to the nanotube thinning. This process emerged, at the first glance, as occurring without any obvious regularities in terms of a type of MWCNT wall defects. Having in mind the observed tendency, we have performed a detailed thermogravimetric analysis (TGA) and the parallel Boehm titration for each sample, further supported by analysis of the main peaks in Raman spectra with a recall of TEM results (Fig. 3). As can be seen, the first weight loss (below $200{ }^{\circ} \mathrm{C}$ ) in TGA curves (Fig. 3A; ESI, Fig. S1 and S2 $\dagger$ ) could be connected with the desorption of water (approx. $2 \mathrm{wt} \%$ ). Further, the weight loss in a range from 200 to $550{ }^{\circ} \mathrm{C}$ could be assigned to desorption of covalently bonded groups and hence, in the first place, to decarboxylation - as the least energy demanding process and straightforwardly correlatable with the $-\mathrm{COOH}$ content $\left(300-550{ }^{\circ} \mathrm{C}\right)$.

In all of the cases, step-wise weight losses could be observed while phenol-type hydroxyl groups were eliminated above $500{ }^{\circ} \mathrm{C} .{ }^{21}$ The exact functionalization degrees were determined by a projection of the Derivative Thermogravimetry (DTG) peak 

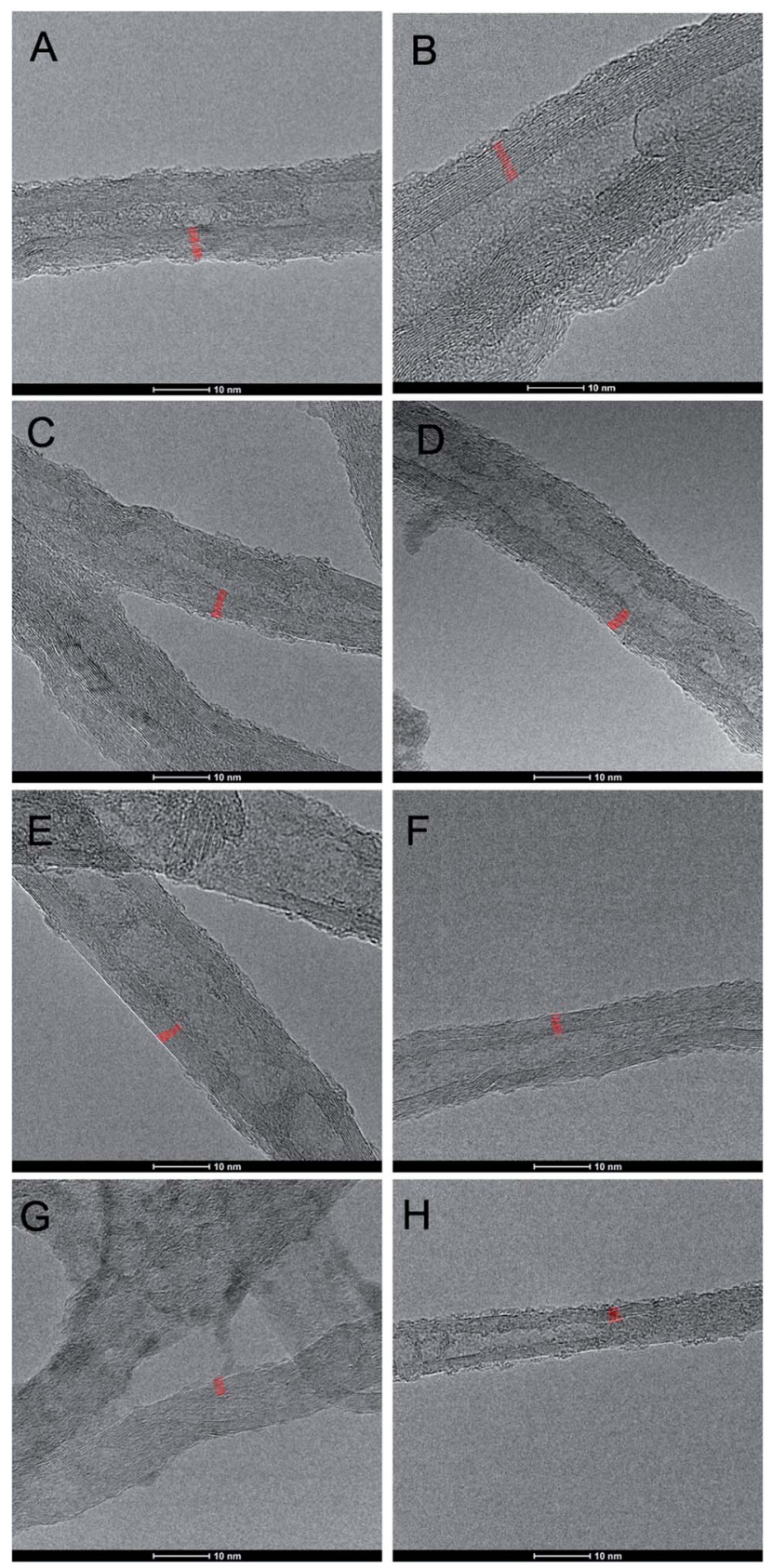

Fig. 2 HRTEM images of representative O-MWCNTs after 5 min (A), $10 \mathrm{~min}(B), 15 \mathrm{~min}(C), 30 \mathrm{~min}(\mathrm{D}), 45 \mathrm{~min}$ (E), $60 \mathrm{~min}$ (F) $75 \mathrm{~min}$ (G) and $90 \mathrm{~min}(\mathrm{H})$ oxidation time. The red lines show the well-graphitized MWCNT walls.

onsets and offsets (hence initiation and termination of the appropriate processes) onto the corresponding TGA curves and readout of the weight differences between the so-indicated points (ESI, Table S1†).

Importantly to note, the trends were non-monotonic and quasi-periodic so they required further verification. Here, with the help came Boehm titration (black curve in Fig. $3 \mathrm{~B}$ ). ${ }^{19}$ Indeed, in line with the TGA results, the $\mathrm{COOH}$ content was changing throughout the whole course of the experiment in a similar, that is the quasi-periodic manner. $(\mathrm{OH}$-content was found constant for all O-MWCNT samples, i.e. $1.8 \pm 0.2 \mathrm{mmol}$
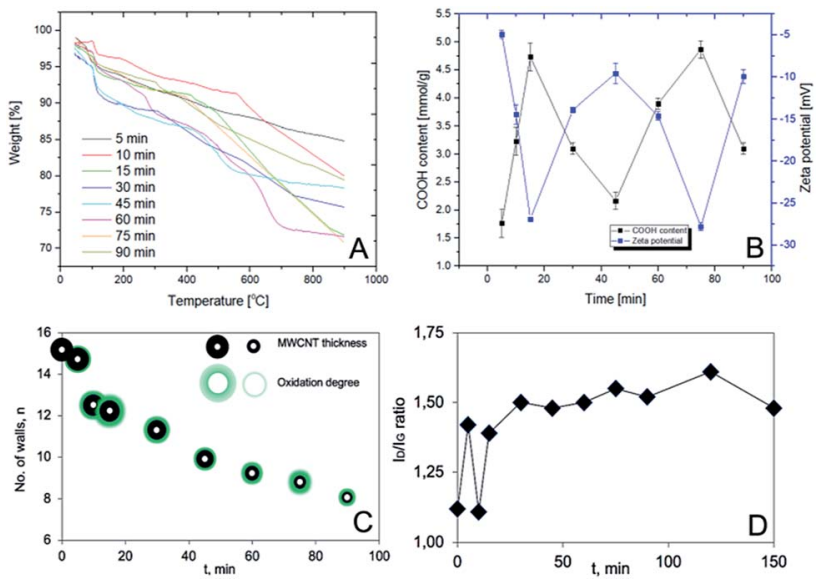

Fig. 3 Representative TGA curves for O-MWCNTs obtained by oxidation at different periods of time (A). Correlation of zeta potential

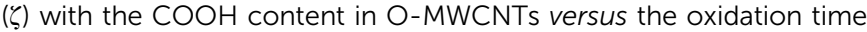
(B). No. of MWCNT walls and degree of the outer wall oxidation (indicated as green layer of varied thickness) versus oxidation time (C). $I_{D} / I_{G}$ ratios in the Raman spectra of O-MWCNT products (D).

$\mathrm{g}^{-1}$ ). As so, any high $\mathrm{COOH}$ content - received from the Boehm titration - could be directly correlated to highly negative zeta potential ( $\zeta$ ) values (blue curve in Fig. 3B). This observation confirmed the elevated surface concentration of negatively charged functional groups. Remarkably, the whole in-time studies allowed stating a clear interdependence between functionalization degrees and the duration of oxidation in this quasi-periodic relationship. Generally, the shape of the Boehm- and $\zeta$-curves must be related to progressing degradation of the most outer walls of MWCNT. This phenomenon, also called 'onion effect' ('layer-by-layer'), has been also very recently observed by González et al. ${ }^{22}$ They observed that several MWCNT walls were peeled off after achieving a critical carboxylic group content during the oxidation by $\mathrm{H}_{2} \mathrm{O}_{2}$ under UV irradiation - partly confirming our findings. However, there are remarkable differences for oxidation with the nitrating mixture, comparing to $\mathrm{H}_{2} \mathrm{O}_{2}$. At first, the number of carboxyl groups increased. Next, the outer wall was destroyed and the number of functionalities decreased. When the entire wall was destroyed the number of functional groups again was starting to increase (Fig. 3C). On the other hand, Raman spectra, in which ratio of intensities of D- to G-peaks $\left(I_{\mathrm{D}} / I_{\mathrm{G}}\right.$ ratio) corresponds to ratio of C-sp ${ }^{3}$ to C$\mathrm{sp}^{2}$ atoms (Fig. 3D), ${ }^{23}$ were found as loosely correlating with the other outcomes. This net effect could result from the fact that distortion from $\mathrm{sp}^{2}$-hybridization derives from: (a) $\mathrm{COOH} / \mathrm{OH}$ surface functionalization, (b) the initial defects in the inner walls, and (c) decarboxylation leaving 'wrinkled' regions in the nanotube walls (clearly seen in TEM images) rich in $\mathrm{sp}^{3}-\mathrm{C}$ atoms.

In order to construct a more general approach taking all the above facts into consideration, we attempted to build an overall kinetic model describing the observations of MWCNT oxidation (Fig. 4) assuming that: (a) the initial number of walls in MWCNT is 15 , (b) the inter-wall distance equals to $0.334 \mathrm{~nm}$, (c) outer 

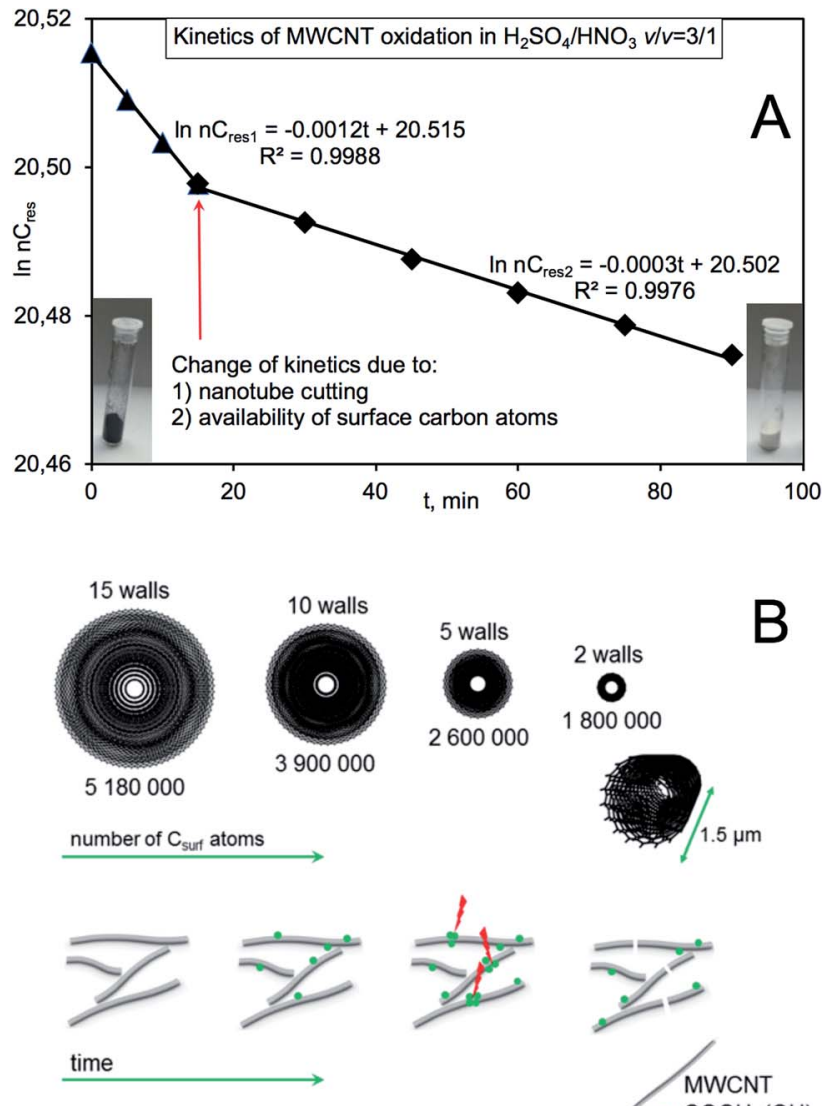

- $\mathrm{COOH},(\mathrm{OH})$

Fig. 4 Complex kinetics of MWCNT oxidation: number of residual carbon atoms (log scale) in O-MWCNTs versus time reveals a pseudo $1^{\text {st }}$ order of MWCNT wall combustion - two neighboring regions of different kinetics are shown (A); qualitative mechanism of MWCNT oxidation: apart from 'layer-by-layer' desheathing via quasi-periodic functionalization leading to nanotube thinning, MWCNTs are cut in the regions of excessive functionalization (reactive hot-spots) (B); a decreasing number of available surface carbon atoms ( $\left.n \mathrm{C}_{\text {surf }}\right)$ is shown for particular nanotube outer diameters for Nanocyl MWCNT length of $1.5 \mu \mathrm{m}$; the insets in (A) show MWCNT before oxidation (left) and after complete carbon digestion (right).

diameter and length are $9.5 \mathrm{~nm}$ and $1.5 \mu \mathrm{m}$, respectively (Fig. 4A), and (d) a local densification of the functional groups (reactive hot-spots) could lead, apart from the nanotube thinning, to its shortening/cutting ${ }^{24-26}$ due to necking functionalization (Fig. 4B). Simplifying that all the walls are of metallic armchair $(n, n)$ configuration, the first wall and the second would be of $(30,30)$ and $(35,35)$ chiral indices. For those indices, a number of carbon atoms in the 'circumference unit' equals 240 and 280, respectively. The iteration to the diameter and length would yield molecular weight of the individual/single $15^{\text {th }}$ wall of $\sim 62$ millions and hence molecular weight of the individual Nanocyl MWCNT $\sim 607$ millions of Daltons. As the oxidation proceeded in the presence of large excess of by oxidants, it could follow the pseudo $1^{\text {st }}$ order kinetics. Generally, the process could be considered from two points-of-view, that is as combustion/removal of wall carbon atoms leading to delamination (decay of substrate) and as production of gases $\left(\mathrm{CO}_{2}, \mathrm{H}_{2} \mathrm{O}\right)$ (formation of products) (Fig. 4A).
The gaseous products are formed by protonation of carboxylic groups and the subsequent dehydration and decarbonylation (with possible in situ oxidation of $\mathrm{CO}$ ) while decarboxylation proceeds via heat-induced decomposition of carboxylates. ${ }^{27}$ As it could be easily noticed, a number of nonoxidized (remaining/residual) carbon atoms could be described by two equations describing two different regions of pseudo $1^{\text {st }}$ order kinetics, i.e. in the initial stage of the reaction up to $15 \min \ln \left(n \mathrm{C}_{\text {res }}\right)=-0.0012 t+20.515$ and consecutively $\ln \left(n \mathrm{C}_{\mathrm{res}}\right)=-0.0003 t+20.502$ with high correlation coefficients (Fig. 4A). The differences might be the consequence of a drop of number of available surface carbon atoms compromised by the increasing O-MWCNT surface contact area. The latter phenomenon is much more pronounced after 90 min of oxidation after which a slope of the line changes to $c a$. -0.003 . And by performing an excessively prolonged reaction course, i.e. after $108 \mathrm{~h}$ of boiling MWCNTs in the nitrating mixture, a complete decay of carbon phase nanomaterials occurred and only insoluble $\alpha-\mathrm{Al}_{2} \mathrm{O}_{3}$ could be detected as the final white product (inset in Fig. 4). It should be also emphasized that after $7 \mathrm{~h}$ of boiling and hence the substantial increase of the solid-liquid interface, the $\mathrm{O}$ MWCNT products could not be filtered off using the PTFE filter of pore size $0.2 \mu \mathrm{m}$.

\section{Conclusions}

We presented the controllable oxidation of MWCNTs using one of the harshest oxidants, i.e. nitrating mixture of concentrated acids $\mathrm{HNO}_{3} / \mathrm{H}_{2} \mathrm{SO}_{4}=1 / 3(\mathrm{v} / \mathrm{v})$. The elaborated control covers competitive processes of selective oxidation to carboxylic groups and the complete wall-degradation. Basing on the obtained results, one might predict the kinetics of oxidation versus delamination and hence steer the processing toward the required characteristics. Additionally, since the redox potential of the nitrating mixture under elevated temperature is high, one might apply more controllable conditions for both oxidants of lower oxidation power as well as nanotubes of different morphology. Our findings clearly mean that prolonged oxidation under harsh conditions does not necessarily yield nanotubes of higher levels of functionalization which is of great relevance in all fields of oxidized nanotube applications from medicine to sensors to nanomaterials engineering.

\section{Conflicts of interest}

There are no conflicts to declare.

\section{Acknowledgements}

The authors are grateful for the financial support from the National Science Centre (Poland) Grant No. 2017/27/B/ST4/ 02748 in the framework of OPUS program. S. Boncel greatly acknowledges financial support from Silesian University of Technology Rector's Professorial Grant No. 04/020/RGP18/0072 and Rector's Pro-Quality Grant No. 04/020/RGJ19/0085. 


\section{References}

1 S. Mallakpour and S. Soltanian, $R S C A d v ., 2016$, 6, 109916109935.

2 I. A. Safo, F. Liu, K. Xie and W. Xia, Mater. Chem. Phys., 2018, 214, 472-481.

3 R. Rao, C. L. Pint, A. E. Islam, R. S. Weatherup, S. Hofmann, E. R. Meshot, F. Wu, C. Zhou, N. Dee, P. B. Amama, J. Carpena-Nunez, W. Shi, D. L. Plata, E. S. Penev, B. I. Yakobson, P. B. Balbuena, C. Bichara, D. N. Futaba, S. Noda, H. Shin, K. S. Kim, B. Simard, F. Mirri, M. Pasquali, F. Fornasiero, E. I. Kauppinen, M. Arnold, B. A. Cola, P. Nikolaev, S. Arepalli, H.-M. Cheng, D. N. Zakharov, E. A. Stach, J. Zhang, F. Wi, M. Terrones, D. B. Geohegan, B. Maruyama, S. MAruyama, Y. Li, W. W. Adams and A. J. Hart, ACS Nano, 2018, 12, 1175611784.

4 B. M. Maciejewska, M. Jasiurkowska-Delaporte, A. I. Vasylenko, K. K. Koziol and S. Jurga, RSC Adv., 2014, 4, 28826-28831.

5 K. A. Wepasnick, B. A. Smith, K. E. Schrote, H. K. Wilson, S. R. Diegelmann and D. H. Fairbrother, Carbon, 2011, 49, 24-36.

6 S. S. Ba Hashwan, M. F. Fatin, A. R. Ruslinda, M. K. Md Arshad, U. Hashim and R. M. Ayub, Appl. Mech. Mater., 2015, 754-755, 1156-1160.

7 G. A. Forrest and A. J. Alexander, J. Phys. Chem. C, 2007, 111, 10792-10798.

8 Y. Kanai, V. R. Khalap, P. G. Collins and J. C. Grossman, Phys. Rev. Lett., 2010, 104, 066401.

9 V. Datsyuk, M. Kalyva, K. Papagelis, J. Parthenios, D. Tasis, A. Siokou, I. Kallitsis and C. Galiotis, Carbon, 2008, 46, 833-840.

10 P. S. Goh, A. F. Ismail and M. Aziz, AIP Conf. Proc., 2009, 1136, 224-228.

11 I. D. Rosca, F. Watari, M. Uo and T. Akasaka, Carbon, 2005, 43, 3124-3131.
12 P. Canete-Rosales, V. Ortega, A. Alvarez-Lueje, S. Bollo, M. Gonzalez, A. Anson and M. T. Martinez, Electrochim. Acta, 2012, 62, 163-171.

13 A. M. Dimiev, A. Khannanov, I. Vakhitov, A. Kiiamov, K. Shikhina and J. M. Tour, ACS Nano, 2018, 12, 3985-3993.

14 D. V. Kosynkin, A. L. Higginbotham, A. Sinitskii, J. R. Lomeda, A. Dimiev, B. K. Price and J. M. Tour, Nature, 2009, 458, 872-876.

15 S. Sarkar and P. K. Das, J. Therm. Anal. Calorim., 2012, 107, 1093-1103.

16 A. K. Singh, X. Hou and K.-C. Chou, Corros. Sci., 2010, 52, 1771-1776.

17 S. I. Al-mayman, N. M. Al-Abbadi and M. A. Atieh, Arabian J. Sci. Eng., 2014, 39, 621-630.

18 R. Brukh and S. Mitra, J. Mater. Chem., 2007, 17, 619-623.

19 Y. S. Kim, S. J. Yang, H. J. Lim, T. Kim and C. R. Park, Carbon, 2012, 50, 3315-3323.

20 C. M. White, R. Banks, I. Hamerton and J. F. Watts, Prog. Org. Coat., 2016, 90, 44-53.

21 L. T. M. Hoa, Diamond Relat. Mater., 2018, 89, 43-51.

22 V. J. González, S. M. Vega-Diaz, A. Morelos-Gomez, K. Fujisawa, M. Endo, O. Martin Cadiz, J. B. Llido and M. Terrones, Carbon, 2018, 139, 1027-1034.

23 M. S. Dresselhaus, A. Jorio, A. G. Souza Filho and R. Saito, Philos. Trans. R. Soc., A, 2010, 368, 5355-5377.

24 J. Li and Y. Zhang, Appl. Surf. Sci., 2006, 252, $2944-2948$.

25 Q. Chen, C. Saltiel, S. Manickavasagam, L. S. Schadler, R. W. Siegel and H. Yang, J. Colloid Interface Sci., 2004, 280, 91-97.

26 S. Boncel, K. H. Müller, J. N. Skepper, K. Z. Walczak and K. K. Koziol, Biomaterials, 2011, 32, 7677-7686.

27 S. A. Chernyak, A. S. Ivanov, N. E. Strokova, K. I. Maslakov, S. V. Savilov and V. V. Lunin, J. Phys. Chem. C, 2016, 120, 17465-17474. 